\title{
HERITAGE: THE PRICELESS HOSTAGE OF ACCRUAL ACCOUNTING
}

\begin{abstract}
Purpose: The objective of this paper is to examine how the convergence of private and public sector accounting standards is affecting conceptual and practical issues relating to heritage. More specifically, the paper is intended to provide a better understanding of the state of the art in national and international accounting standards on heritage assets, and of the views influencing such standards.
\end{abstract}

Design: A qualitative documentary analysis is carried out to explore the variety of existing positions and views on heritage, ranging from the scholarly literature, through potential stakeholders and users, to international and national standard setters.

Findings: The analysis shows that the path of convergence between public and private sector standards and practices is still problematic. After more than two decades of debate around the nature, definition, measurement, and reporting of heritage, these issues are far from settled.

Value: Looking at European national standards for heritage, the IPSASB's proposals, and the reactions to the latter by relevant stakeholders, the paper provides a pluralistic view on the positions and experiences about heritage, contributing to the debate on the convergence between private and public sector accounting standards.

Implications. In the light of calls for increased measurement and reporting of public sector "assets", and specifically for the definition of standards to recognize heritage, the paper suggests the need to strongly reconsider whether the convergence between public and private sector standards is desirable, feasible, and effective. As such, the risks of embracing simplified or hybrid forms of accounting and reporting for heritage should be more seriously assessed. While reporting on heritage is important, it is fundamental to keep it distinct from reporting on government's regular operations, in order to appreciate its specific value, nature, and features.

Keywords: assets; control; economic benefits; public sector accounting; service potential Article classification: Research paper

\section{INTRODUCTION}

There is a wide, long-established literature documenting how the public and private sectors are different (Rainey et al., 1976; Nutt and Backoff, 1993; Boyne, 2002) and how publicness may 
affect the functioning of governments, the provision of services, and the accountability mechanisms adopted in the public realm (Lapsley, 1988; Boyne et al., 1999; Steccolini, 2019). A parallel literature has developed in accounting scholarship, discussing the (un)suitability of private sector techniques, standards, and perspectives for public sector accounting (e.g., Ellwood and Newbury, 2006; Grossi and Steccolini, 2015). In practice, however, private and public sector accounting standards appear to be on a convergence path, encouraged by the accounting profession and by international and supranational institutions. In the absence of consolidated standards for the public sector, and in the face of difficulties in the recognition and measurement of items which are typically found in the public sector, such as heritage, private sector practices and standards, or convergence towards them, have been often suggested as a possible solution. This is evident, for example, in the IPSASB's approach to standard setting, whereby "the IPSASB's objective is to serve the public interest by developing highquality accounting standards [...]" so as to "enhance the quality and transparency of public sector financial reporting by providing better information for public sector financial management, accountability and decision making". In pursuing this objective, "[...] the IPSASB supports the convergence of international and national public sector accounting standards and the convergence of accounting and statistical bases of financial reporting where appropriate; and also promotes the acceptance of its standards and other publications." 1 The interpretation of the "convergence" concept is clarified, for example, in the IPSASB's Strategy and Work Plan for 2019-2023, where the IPSASB's strategic objective is described as "strengthening Public Financial Management (PFM) globally through increasing adoption of accrual-based IPSAS"2. As such, the convergence path is strictly focused on applying accrualbased standards, which draw, to the extent this is deemed possible, on existing private sector standards ${ }^{3}$.

Paradoxically, however, the reference to the private sector appears to have created new problems, with the recognition and evaluation of such items as heritage assets becoming the subject of endless debates among both scholars and practitioners.

This paper aims at shedding new light on how current processes of convergence are taking place in practice. It focuses on heritage assets because, compared to other public sector assets, their elements of publicness are particularly pronounced and are seen as an "extreme case of accounting difficulty" (Biondi and Lapsley 2014: 159). As such, the debate on whether heritage assets can be evaluated or not (thus becoming "priceless") has become a never-ending issue, whereby the case of heritage assets has been taken to signify and symbolize alternatively the difficulties of adopting accruals accounting, and its potential benefits. More specifically, the paper is intended to provide a better understanding of the state of the art in national and international accounting standards on heritage assets, and of the views influencing such standards. To this end, it explores the variety of existing positions and views on heritage,

\footnotetext{
${ }^{1}$ https://www.ifac.org/node/1503/terms-reference, accessed on 23/05/2019

2 https://www.ifac.org/publications-resources/ipsasb-strategy-and-work-plan-2019-2023, accessed on $23 / 05 / 2019$

${ }^{3}$ Indeed, the IPSASB's website offers an "IPSAS-IFRS alignment dashboard" showing how far individual IPSASs are aligned with corresponding IFRSs (https://www.ipsasb.org, accessed on 25/05/2019)
} 
ranging from the scholarly literature, through potential stakeholders and users, to international and national standard setters, with a particular emphasis on the IPSASB's (2017a) Consultation Paper on Heritage and the related response letters (IPSASB, 2017b). This allows an assessment of whether the (often called for) convergence is actually taking place for heritage assets, or rather whether divergent approaches and views are still emerging and remain alive.

The next section reviews the relevant literature. The third section describes the research methodology. The fourth section presents the results, which are further discussed in section five, where conclusions and implications for practice and research are drawn.

\section{LITERATURE REVIEW}

This section reviews the extant literature on the accounting treatment of heritage assets, pointing to the existence of significant contention about both (i) the recognition of heritage assets in the general purpose financial reports of governments, and (ii) their measurement and disclosure.

\subsection{Recognition of heritage assets}

Heritage assets are not easy to define. The following distinctive characteristics have generally been identified in the literature (Mautz, 1988; Barton, 2000, 2005; Adam et al., 2011): (i) they are characterized by historic, artistic, architectural, aesthetic, scientific, technological, geophysical, or environmental features; (ii) they are held by governments that have the duty to conserve and maintain them in good condition for the benefit of current and future generations; (iii) they are made available without discrimination by governments to the general public, and their benefits flow to the users rather than to the managing entity; (iv) they are mainly funded from taxation revenues and/or private donations, with user charges, if any, covering only a small part of the cost incurred for their maintenance and operation; (v) they are unlikely to be traded, also because legislation often exists that prohibits or restricts their disposal by sale to protect their social purposes; (vi) they generally cannot be reproduced or replaced; (vii) their useful life is often indefinite; (viii) they usually have no market price or relevant acquisition cost; and (ix) their social value is not properly expressed in commercial valuations.

In the light of these unique characteristics, whether heritage items should be considered as assets of the government for general purpose financial reporting has become the subject of a lively debate among scholars. Two main contrasting positions have emerged. For some scholars, heritage items are regular assets; for others, they fail to comply with the general definition of an asset. In particular, two essential elements of the general definition of an asset warrant attention, namely, control by the entity and economic benefits.

Control is the condition that guarantees the entity's ability to derive the benefits embodied in an asset. Control generally entails private ownership arising from a past event. However, it has been pointed out that the concept of private property is not appropriate for several public assets, 
such as infrastructural, cultural, and environmental assets, including highways, historical monuments, museums, public libraries (e.g., Pallot, 1992; Barton, 2000, 2005) and collections (Glazer and Jaenicke, 1991; Carnegie and Wolnizer, 1995). The private property regime implies that the owner has legal title to the asset and all the relevant substantive rights (i.e. custody, usufruct, alienation, and destruction). For several assets, however, the government has the title of owner and the duty to maintain and repair, but it is not the beneficiary of their use. The benefits accrue to the public to whom the assets are made available. Moreover, the government often does not have the right to alienate these assets or to exclude members of the community from their use. Pallot (1992) suggested the concept of community assets, referring to situations where the government has the duty to manage the asset and to make its use available to the public, but it does not have usufruct, nor the right of alienation or destruction. Along similar lines, Barton $(2000 ; 2005)$ suggested that heritage items should be classified as trust assets, since they are not owned by the government, but rather by citizens. The government holds them in trust and manages them as public goods for present and future generations; thus, it has the duty to protect and preserve them. They cannot be sold, nor are they available to help repay liabilities. As such, they should not be included in the government's balance sheet.

In this last respect, it is worth emphasising that exclusion from financial reports does not mean that the reporting entity abdicates its responsibilities to protect and manage heritage resources. Conversely, responsibility for the protection and management of these items does not imply that they should be included in the relevant government's balance sheet. The literature suggests other forms of reporting, including both financial and non-financial information, that would be appropriate for accountability and management purposes (see section 2.2).

The traditional definition of assets, moreover, generally refers to economic benefits for the controlling entity, including cash inflows or reduced cash outflows, generated through the use of an asset in the provision of services or through its direct exchange. However, several scholars have pointed out that heritage assets do not generate economic benefits. On the contrary, they may even generate losses or outflows. In a renowned paper, Mautz (1988) provocatively suggested that, since heritage assets entail losses, they should be recorded as liabilities. Similarly, Barton (2005) argued that heritage assets do not produce economic benefits either through use by citizens, as they are freely available or charged at below-cost prices, or through their sale, since their disposal by the government is forbidden or subject to limitations. For these reasons, heritage assets should be treated separately from operating assets and should not be reported in the financial statements. Similar considerations were developed by Carnegie and Wolnizer (1995) with reference to art collections. Conversely, a different view has been proposed whereby items that do not generate economic benefits must still be classified as assets for financial reporting purposes to the extent that they embody "service potential" (Micallef and Peirson 1997). An asset embodies service potential when it is able to assist an entity in the pursuit of its objectives (IPSASB, 2014). In other words, this concept of "service potential" is put forth to expand the scope of assets' definition to include also non-economic benefits, such as the provision of desired services to beneficiaries. 
To sum up, heritage items have been shown not to fulfil the traditional criteria for the recognition of assets, namely, control and economic benefits. With regards to economic benefits, however, the IPSASB has introduced the concept of "service potential" for qualifying an asset in the public sector. The reference to service potential provides the cornerstone for the position that heritage items should be considered as assets for public-sector financial reporting purposes.

\subsection{Heritage asset measurement and disclosure}

Recording a heritage item in the balance sheet, either as a regular fixed asset or as a distinctive type of asset, requires giving it a value that should be reliably measured (Stanton and Stanton, 1997). When difficulties emerge in this respect, recognition in the financial statement should be avoided, because it may negatively affect decision making about the allocation of scant resources and the discharge of government's accountability obligations (Carnegie and Wolnizer, 1996; Aversano and Christiaens, 2014). With specific reference to the measurement of heritage assets, several issues have been highlighted in the literature.

First, markets for heritage assets often do not exist or are very thin (Barton, 2000, 2005; Biondi and Lapsley, 2014). Thus, it is hard to obtain a market price at which heritage assets may be measured. Moreover, even when a market does exist, the prices are often volatile and subjective, and the cost of their calculation often exceeds the potential benefit (Ström, 1997; Ellwood and Greenwood, 2016).

Second, several alternative valuation methods have been proposed, such as replacement cost, replication cost, and historical cost. However, their application to heritage raises several concerns (Stanton and Stanton, 1997; Barton, 2000, 2005; Aversano and Christiaens, 2014; Ellwood and Greenwood, 2016). Replacement or replication cost is generally viewed as inappropriate for heritage items, such as paintings or sculptures, because their value depends not only on their material components, but especially on the fact that they belong to a specific historical period and/or have been created by a specific artist. As to historical cost, it may be objective, but it is not always available (Carnegie and Wolnizer, 1995, 1999), for instance when heritage assets were acquired by gift, discovery, or accretion; alternatively, it may not be identifiable, especially when assets were acquired by the reporting entity long ago (Barton, 2000). Moreover, historical cost has been argued to be irrelevant for management and accountability purposes because it is not representative of the asset's current value (Harris and Murti, 1998; Carnegie and Wolnizer, 1999; Barton, 2000). Once again, a different view is held by Micallef and Peirson (1997: 33), who claim that the provision of whatever historical cost information is available would "be better than no information about those assets".

Third, a more general question discussed in the literature is whether any financial/commercial value attributed to a heritage asset is capable of capturing its social value. Proponents of financial valuation and inclusion of heritage in general purpose financial statements believe that social values stemming from heritage assets can be financially quantifiable (Hone, 1997; Micallef and Peirson, 1997). Opponents argue that financial valuations cannot serve as reliable 
proxies for the social value of heritage assets (e.g., Carnegie and Wolnizer, 1996) because they crowd out the attention of management and policy makers from the focus on social aspects and the value for citizens and the community (e.g., Stanton and Stanton, 1997; Barton, 2000). For example, Ellwood and Greenwood (2016) contend that economic value and social value are "rivals", with one value necessarily detracting from the other. Biondi and Lapsley (2014) claim that a mixed approach is needed to increase transparency on heritage assets, which combines financial information with wider information on their cultural significance and societal impact.

In the light of the problematic nature of heritage asset measurement, a large number of scholars favour the implementation of alternative information systems. Barton (2000) recommended that all financial and non-financial information related to heritage assets should be reported separately from the general purpose financial statement. In terms of non-financial information, he mentioned architectural and cultural significance, physical condition, and need for major restoration. Moreover, he recommended providing measures of performance, such as numbers of visitors and levels of visitor satisfaction. As to financial information, a specific statement of income and expenditure should show the revenues received in the form of public grants, private donations, sponsorships, and fees from visitors, as well as the expenditures incurred for restoration, maintenance, and acquisition of new assets. Similarly, for social/cultural facilities, Christiaens et al. (2012) suggested disclosing, in the notes to the government's financial statements, several descriptive details on the assets held, as well as financial valuations should it be possible to identify reliable values. Information about expenses and revenues generated by transactions related to social/cultural assets should be reported in the operating statement. With specific reference to collections, Carnegie and Wolnizer (1995, 1996) proposed substituting the assignment of "spurious and uninterpretable values" to heritage assets with a combination of practices, techniques, measures, and reports, such as collection inventories, performance indicators, budgetary planning and management, which would enable museums to be accountable. Considering that, on the one hand, it is often impossible to attribute a reliable financial value to heritage assets, and, on the other, it is hard to objectively value their social dimension, Stanton and Stanton (1997) posited that a non-financial focus may be preferable to guarantee accurate information on all heritage assets. Interestingly, Aversano and Christiaens (2014), looking at the information needs expressed by politicians (mayors and councillors) about heritage assets, provide empirical support to this position, highlighting that politicians would prefer other qualitative information to non-representative and partial representation in the balance sheet, such as information on costs of custody, physical condition, and policy for preservation.

In a nutshell, the literature thus highlights that: (i) heritage items have features that make them conceptually distinct from regular assets; (ii) their inclusion on the asset side of the balance sheet, even in a separate category, is often impossible for the lack of appropriate measurement bases; (iii) even if possible, such inclusion may be inappropriate due to several reasons, such as partial representation of heritage assets, crowding-out of their social value, and overstatement of the managing entity's financial viability; (iv) still, information is needed for accountability and decision-making purposes; and (v) such information may be better provided through supplementary reports. 


\section{RESEARCH METHODOLOGY}

The objective of this paper is to examine how the convergence of private and public sector accounting standards is affecting conceptual and practical issues relating to heritage. The criteria for the recognition of assets were developed for the private sector, and then made applicable for the public sector context. As pointed out above, however, various studies in the literature have shown that heritage assets do not fulfil these criteria. In spite of this, the debate on how accrual-based financial statements are to incorporate them persists, culminating in the issue of another Consultation Paper on the subject by the IPSASB. How shall the IPSASB embrace the particularities of heritage assets? Shall it take into consideration the practical issues faced by national standard setters when attempting to deal with financial reporting of heritage assets? Or shall the IPSASB "capture" heritage assets in its rhetoric that private sector concepts should apply just as well in the public sector?

In order to achieve the paper's objective, documentary analysis was used to assess the state of the art in accounting standards and stakeholder perspectives concerning heritage asset reporting. The documents analysed include: (i) the IPSASB's "Consultation Paper on Financial Reporting for Heritage in the Public Sector" (IPSASB, 2017a), henceforth referred to as "the Consultation Paper"; (ii) the 40 comment letters received by the IPSASB on the Consultation Paper (IPSASB, 2017b); and (iii) National accounting standards on heritage assets. The focus on the Consultation Paper is explained by the fact that the IPSASB is the only international public sector accounting standard setter, whose standards have gained increased recognition, application and attention over the last few decades. The response letters were intended to provide a better understanding of current stakeholder positions and perceptions. As for the national standards, they were used to capture the degrees of variation in the approaches adopted by national standard setters, who face specific local conditions (e.g. in the nature and amount of heritage assets) and local sensitivities (e.g. in the perception of the trade-off between economic and social value), but who have all been required to reconcile conceptual rigour with practical feasibility.

In the collection of national standards, Europe was the main focus. Europe is an interesting setting for such an analysis, because of the current process concerning the development of European Public Sector Accounting Standards ${ }^{4}$. It is also characterized by commonalities in regulations due to EU membership for several countries, while at the same time presenting a variety of administrative traditions (Meyer and Hammerschmid, 2010; Pollitt and Bouckaert, 2011).

\footnotetext{
${ }^{4}$ A study carried out by the European Commission's Eurostat in 2012 had concluded that IPSAS are not suitable for EU member states. The Commission then embarked on a project to develop public sector accounting standards that are more applicable for the European context, albeit referring to IPSAS.
} 
The national accounting standards included in this analysis were identified through a web search and/or by obtaining information from other academics contacted by email. More specifically, the countries were chosen as follows:

a) France, Lithuania, and the German State of Hesse because they were covered by a recent study by EY (2017);

b) The UK, because the Financial Reporting Manual followed by the UK Treasury is available in English from the website;

c) Two countries were chosen because the authors are resident there and thus have access to, and can understand, the national accounting standards; and

d) Another nine countries were chosen on the basis of email correspondence with academics who are resident there. The academics were asked whether the respective countries followed any publicly available standards/rules which explicitly regulated accounting for heritage assets. If so, and the standard/rule was in English, the academics were asked to provide a soft copy or an electronic link. Conversely, if the standard/rule was not in English, the academic was asked to provide the name of the standard/rule as well as information related to each of the six themes emanating from the IPSASB's Consultation Paper, namely, (i) description of heritage items; (ii) heritage items as assets (for example: is there a distinction between operational and non-operational heritage assets? Are intangible heritage items considered? Are they accounted for like any other asset?); (iii) recognition and initial measurement; (iv) subsequent measurement; (v) recognition of obligations stemming from the intention to preserve heritage items; and (vi) presentation of information about heritage (i.e. further disclosure requirements).

Only those countries whose documents were accessible were taken into consideration. It is worth mentioning that the scope and quality of regulation on heritage assets was found to vary significantly. At the same time, attention was devoted to ensure that the final group of 15 jurisdictions represented different sizes, geographic areas, and administrative traditions (Appendix, Table A). In this last respect, the 15 jurisdictions cover the Anglo-Saxon tradition (UK, Ireland, and Malta) as well as several Continental ones: "Napoleonic"/Southern EU countries, including Belgium, France, Greece, Italy, Spain, and Portugal; Rechtsstaat countries, including Austria and the German State of Hesse ${ }^{5}$; Eastern European, former Communist or Socialist countries, including Croatia, Lithuania, and Poland; and Scandinavian countries, represented by Sweden.

The analysis of the documents mirrored the structure of the Consultation Paper and consequently, it was developed along the six identified themes.

\section{FINDINGS}

\footnotetext{
${ }^{5}$ The State of Hesse is included because it is a state in the Federal Republic of Germany with a high accounting maturity (EY, 2017). The authors are not implying that the State of Hesse represents the whole of Germany.
} 
This section presents the results of the documentary analysis along the six above identified themes. For each theme, the IPSASB's proposal is compared and contrasted with national experiences and the responses to the consultation process.

\subsection{Description of heritage items}

The IPSASB had first encountered the challenge of accounting for heritage when it developed IPSAS 17 'Property, Plant and Equipment' and IPSAS 31 'Intangible Assets'. These two standards, which are based on their private sector counterparts (IASs 16 and 38, respectively), contain paragraphs which describe heritage assets, but allow preparers to decide how to account for heritage (IPSASB, 2017a).

The Consultation Paper, first identifies the particular characteristics of heritage items and the challenges they represent for financial reporting - which are practically the same as those already identified in the extant descriptive paragraphs found in IPSAS 17 and IPSAS 31 - and then proposes a definition of heritage items that captures these characteristics and challenges. Throughout the rest of the Consultation Paper, the IPSASB seeks to identify the type of heritage-related information that users of general purpose financial reports would need for the purposes of accountability and decision making (IPSASB, 2017a).

The analysis of national standards points to a significant variety of approaches to the description of heritage items, probably encouraged by the loose framework defined by IPSASs 17 and 31. Three countries included in this study, namely, Greece, Poland, and Sweden, choose not to refer to heritage at all. The other countries, irrespective of whether they are traditionally Anglo-Saxon or continental European, have varied practices, with the main difference being the application of a rules-based or a principles-based approach (Appendix, Table B).

Austria, Hesse, Portugal, and Spain (Continental European) apply a principles-based approach, similar to the UK, Ireland, and Malta (Anglo-Saxon). On the other hand, Belgium and Croatia do not attempt to define heritage, but then make references to specific categories. France applies the strictest rules-based approach, where heritage assets are listed in an annex to the French standard and are defined objectively by classification and registration procedures. A rules-based approach is also evident in Italy, where heritage assets are defined in the law as a subset of 'public domain assets', that is, assets that can only be owned by governments, cannot be sold, and whose related rights cannot be otherwise transferred; however, public domain assets in general and heritage assets in particular are not specifically identified in detailed lists. Lithuania combines both approaches by identifying three categories of tangible heritage items: movable and immovable cultural objects, and other objects. Movable and immovable cultural objects are listed in the Register of Cultural Objects of the Republic of Lithuania (rules-based), while a principles-based approach is used for other valuables. The German State of Hesse also lists some of the items considered as heritage (EY, 2017).

This variety of approaches is not mirrored in the IPSASB's proposal, which continues to support the principles-based approach. The Consultation Paper (IPSASB, 2017a: 15) provides 
the following description of heritage items, reflecting their special characteristics that distinguish them from other elements in financial reporting:

\begin{abstract}
Heritage items are items that are intended to be held indefinitely and preserved for the benefit of present and future generations because of their rarity and/or significance in relation, but not limited, to their archaeological, architectural, artistic, cultural, environmental, historical, natural, scientific or technological features.
\end{abstract}

According to the Consultation Paper (par.1.7), the characteristics of heritage items include the fact that they are often not replaceable; not transferable due to ethical and/or legal restrictions/ prohibitions; and have a long (or indefinite) useful life due to increasing rarity and/or significance. As a consequence of these characteristics, heritage items pose financial reporting challenges with respect to measurement, value, preservation, restrictions on use, and benefits to others (par.1.8).

Some of the responses received by the IPSASB appear to appreciate the presence of significant challenges in practice. More than half of the respondents (55\%) agreed both with the identified characteristics and challenges, and that the proposed description of what constitutes heritage items captures such characteristics and challenges. Among the remaining respondents, half did not agree and the other half agreed only partially in that they would state an overall agreement, but then qualify it by raising specific issues, highlighting "areas for potential improvement", relaying that "in our discussions some comments and questions arose", suggesting "that the Board considers the following additional points". The significant presence of disagreements and qualifications suggests that the IPSASB is understating the special nature of heritage items and the resulting consequences for financial reporting.

More specifically, some respondents pointed out that the description should be revised to better capture the range and characteristics of heritage items; it should also be made more precise so that it can operate as a definition. Others were more supportive of a rules-based approach because they found that the proposed definition is too wide and it would lead to subjectivity in the identification of heritage items.

Some respondents highlighted that heritage items increase in value over time. This seems irrelevant to respondents who emphasized that heritage items cannot be measured, and thus should not (or cannot) be represented in financial reports. On the contrary, one respondent argued that the financial reporting challenges are overstated because anything can be valued.

A final consideration refers to the distinction between operational and non-operational assets, which is present in IPSAS 17 and 31, but is embraced by only four countries of those analysed. Among the respondents, a few requested a clearer distinction between operational and nonoperational heritage items, together with more guidance as to the significance of such a distinction. Others, conversely, pointed to the potential irrelevance of such distinction. 
In general, the responses do not support the IPSASB's suggestions regarding natural heritage, and also point to uncertainty about intangible heritage items. The responses illustrate how personalized the definition of heritage could be, as the importance and relevance of heritage varies across jurisdictions, as also reflected in the diverse treatment in national accounting standards.

All the above considerations highlight how the argument on the definition is unavoidably linked with whether heritage items can be considered as assets at all.

\subsection{Heritage items as assets}

All the national accounting standards start from the premise that heritage items are assets for financial reporting purposes, provided that they satisfy certain conditions. For countries that adopt a rules-based approach, like France, a heritage item is an asset if it is included in the list annexed to the law. For countries that adopt a principles-based approach, like the German State of Hesse, Portugal, Spain, and Malta, heritage items are assets if they satisfy the definition of an asset. This is also the normal treatment in IPSAS and IPSAS-like standards, including Ireland and the UK.

The IPSASB's proposal in the Consultation Paper is that the special characteristics of heritage items do not prevent them from being considered as assets for the purposes of financial reporting. This proposal is based on an analysis of three aspects of the definition of an asset as provided in the IPSASB's Conceptual Framework - resources, control, and past event. Significantly, these are the same aspects that have already been intensely discussed in the literature.

Past event refers to different ways how an entity can acquire control of a heritage resource. The method of acquisition is inextricably linked with control and the same arguments apply.

The IPSASB's Conceptual Framework defines a resource as an item with service potential or the ability to generate economic benefits. The inclusion of "service potential" effectively makes it possible to qualify any item as a regular asset (Christiaens, 2004). Quite naturally, the IPSASB considers heritage items to be more likely held for their service potential, that is, to provide services that contribute to the achievement of a public entity's objectives.

The IPSASB is rather cautious when describing how an entity can have control over heritage resources, using terms like "an entity is likely to have the ability to control ..." (IPSASB 2017a: 17). This is envisaged if the entity can demonstrate that it has legal ownership and/or other enforceable rights, like, for example, the ability to restrict access to a heritage item, or to direct the use of the resource to achieve its objectives.

The concept of control has been heavily criticized in the literature (refer to section 2.1). Despite this, the IPSASB (2017a) still concludes that the special characteristics of heritage items do not prevent them from being resources that are presently controlled by an entity as a result of a past event. Thus, all heritage items could be assets, except for the intangible cultural heritage called 
"knowledge-in-action", such as languages, performing arts, rituals, and traditional craftsmanship. The Consultation Paper acknowledges that this type of intangible cultural heritage does not meet the definition of an asset because such "live" activities cannot be owned or controlled by a single entity - they are "owned" by the whole community.

The IPSASB's conclusion that the special characteristics of heritage items do not prevent them from being considered as assets for financial reporting purposes was (fully or partially) supported by $90 \%$ of the respondents. However, most of these respondents still expressed doubts mirroring the issues already raised in the literature: about the meaning of control; the restrictions on transfers/sales; the ability to measure reliably; the existence of service potential or future economic benefits. Only three respondents totally disagreed with the IPSASB's proposal, highlighting, respectively, the need for more specific indicators of economic benefits and service potential; the fact that the element of control is difficult to satisfy due to the stewardship/custodial role of public entities; and the inappropriateness of the term "asset" for heritage items since these have nothing to do with the financial position and performance of a reporting entity - heritage items are the inheritance of a community over generations, like "family heirlooms", and are thus priceless.

\subsection{Heritage recognition and initial measurement}

In national accounting standards, the rules on the recognition and initial measurement of heritage assets (as summarised in the Appendix, Table C) reflect and confirm many of the conceptual and practical issues raised in the academic literature. They also highlight that, for heritage assets, the key measurement issue is not for new acquisitions, but rather for items acquired before the opening balance sheet's date. This is because, as the word "heritage" implies, it is in the very nature of these items to have indefinite lives and to have been passed down from previous generations.

The UK and Ireland appear to pursue an overall consistency with private sector standards by distinguishing between operational and non-operational heritage assets; by requiring that the former be accounted for in the same way as regular property, plant and equipment; and by prescribing that the latter also be recognized, using such initial measurement bases as fair value (UK) or historical cost (Ireland), if available. Significantly, however, both the UK and Ireland permit non-recognition when reliable measurement is impossible.

At the other end of the spectrum, the most explicit and comprehensive counterexample is provided by the French standard, which places an explicit emphasis on the "symbolic character of heritage asset valuation". Thus, recognition at market value is "ruled out". At the standard's effective date, heritage assets were recognised "at the value of a token euro", unless they had previously been recognised at a different value. As for new acquisitions, valuation is at cost, except for heritage assets received at no cost, which are recognised at expert appraisal value. 
Significantly, many other countries chose to effectively evade the issue, by making a general reference to IPSAS (Portugal) or by regulating the matter only sparsely (e.g. Belgium, Croatia, Italy).

In its own analysis of recognition criteria and measurement objectives for heritage assets, the Consultation Paper acknowledges quite extensively the peculiar conceptual and practical issues posed by such assets. Having determined that the special characteristics of heritage items do not prevent them from being considered as assets for the purposes of financial reporting, however, the IPSASB continues along the same path by stating that:

\section{Heritage assets should be recognized in the statement of financial position if they meet the recognition criteria in the Conceptual Framework (PV-Ch. 4.1).}

In this respect, it is worth mentioning that, according to the IPSASB's Conceptual Framework, one of the conditions for recognising an item in the financial statements is that its measurement be sufficiently relevant and representationally faithful (par. 6.7). Per se, therefore, the reference to the Conceptual Framework would still allow non-recognition of heritage items whenever proper measurement is demonstrably impossible. Despite the criticism raised in the literature, the difficulties encountered by national regulators, and its own preliminary considerations, however, the IPSASB put forward the preliminary view that:

In many cases it will be possible to assign a monetary value to heritage assets. Appropriate measurement bases are historical cost, market value and replacement cost (PV-Ch.4.2). [Emphasis added]

The Consultation Paper then probed respondents on three specific matters, namely: (i) whether heritage assets should be initially recognised at one currency unit; (ii) whether there may be situations in which heritage assets should not initially be recognized and/or measured; and (iii) whether the IPSASB should provide any additional guidance to enable the application of the proposed measurement bases. Significantly, on the matter of valuation at one currency unit, the Consultation Paper insists on its consistency with the historical cost approach, so that it would apply "when an asset was fully depreciated before being categorized as a heritage asset and transferred to the entity, or an entity obtains a natural heritage asset without consideration" (par.4.17 and SMC - Ch. 4.1).

Consistent with the respondents' widespread agreement that the special characteristics of heritage items do not prevent them from being considered as assets for the purposes of financial reporting, the large majority (78\%) also agreed with the IPSASB's proposal that heritage assets should be recognized in the statement of financial position if they meet the recognition criteria in the Conceptual Framework. The overwhelming support for recognition, however, was not unconditional.

First of all, many "agree" responses (28\%) also agreed with initial measurement at one currency unit. This leaves a much lower level of support for "recognition applying measurement bases 
other than one currency unit", i.e. only $50 \%$ of respondents. Despite the IPSASB's insistence on consistency with the historical-cost approach, those supporting valuation at one currency unit generally did so by highlighting the difficulty of heritage measurement, the meaning of the resulting information, and the appropriateness of using a symbolic value.

Even more significantly, the majority of respondents (67\%) acknowledged the existence of situations where heritage items should not initially be recognized and/or measured. Responses focused on measurement difficulties; inability to assign a relevant and verifiable monetary value; and measurement costs that exceed the benefits. In other words, even those who agreed with recognition in principle, could not deny the existence of major conceptual and practical hurdles. The Council of Australasian Museum Directors (CAMD), for instance, challenged the view that monetary values for heritage "increase the inherent understanding of a heritage asset for management purposes." In their opinion, such view "is demonstrably false. The Australian experience, involving over twenty years of market testability in valuation and audit function has failed to produce a coherent, consistently applicable methodology within or between jurisdictions, resulting in fluctuation in the valuation of even high-value, well understood assets. This has led to collection valuations fluctuating over time and jurisdictional authorities refusing to accept the results of valuations".

Finally, only $35 \%$ of respondents fully agreed with the IPSASB's view that "in many cases it will be possible to assign a monetary value to heritage assets" and that "appropriate measurement bases are historical cost, market value, and replacement cost". The dissenters highlighted that particular measurement bases would be unavailable, inappropriate, or irrelevant. The International Consortium on Governmental Financial Management (ICGFM), for example, pointed out that "heritage assets [...] generally do not have active, open and orderly markets"; that, "even where a market exists, [...] restrictions on disposal will make such a value inappropriate"; that, "by their nature, heritage assets are typically irreplaceable". This "only leaves cost as a valuation base. However, many heritage assets have no cost, or only some items of a collection have a cost, or the acquisition was so long ago as to make the cost meaningless. Our conclusion is therefore that it is only exceptionally that a monetary value can be assigned to a heritage asset". Unsurprisingly, $80 \%$ of respondents also identified additional guidance that the IPSASB should provide.

\subsection{Subsequent measurement}

Under the heading of subsequent measurement, the Consultation Paper addresses four topics: (i) capitalisation of subsequent expenditures related to heritage assets; (ii) depreciation and amortization; (iii) impairment; and (iv) revaluation, where a revaluation model is applied.

In the national standards, subsequent measurement is often tackled rather marginally (Appendix, Table D), possibly because it is truly relevant only for countries that have introduced accrual accounting. In most cases, national regulators have seemingly attempted to contextualise the general rules for regular (public sector) fixed assets to the peculiarities of heritage, usually by stating overarching exceptions or qualifications. For example, depreciation 
is generally excluded, either explicitly or as an implicit consequence of heritage assets having indefinite lives; while impairment is usually associated only with lasting physical damage or doubtful authenticity. The only topic that has been devoted significant attention, at least in some countries, is the capitalisation of subsequent expenditures (e.g. restoration and renovation). In this respect, many national regulators have simply reiterated the rules for regular fixed assets, but two main exceptions stand out: on the one hand, the prescription that subsequent expenditures always be expensed (Hesse, Lithuania), presumably to compensate for the absence of depreciation; on the other, the recognition of such expenditures as a new asset "in addition to and separate from the underlying [heritage] asset", followed by depreciation and impairment according to the rules for regular fixed assets (France).

The Consultation Paper, conversely, assumes that no contextualisation is necessary and that all subsequent measurement issues simply:

... can be approached in broadly the same way as subsequent measurement for other, non-heritage assets (PV-Ch. 5).

Nevertheless, the IPSASB probed respondents on whether there may be "any types of heritage assets or heritage-related factors that raise special issues for the subsequent measurement" (SMC - Ch. 5).

On whether subsequent measurement can be approached in broadly the same way for both heritage and regular fixed assets, more respondents disagreed (45\%) than agreed (37\%). The areas of disagreement covered all four aspects of subsequent measurement. The issues raised included: lack of usefulness of the resulting information; inability to determine consumption given an indefinite useful life; cost-benefit issues for revaluation and impairment; and proposals that subsequent expenditures always be expensed. A large number of respondents (62\%) also identified situations that raise special issues for the subsequent measurement of heritage assets. Once again, therefore, the overwhelming support for the recognition of heritage assets was qualified by a two-fold widespread perception: on the one hand, that the special characteristics of heritage require ad hoc technical solutions and cannot simply be waved aside through a general reference to regular assets; on the other, that such solutions are not readily available.

\subsection{Obligations related to heritage items}

A particular issue that is addressed in the Consultation Paper (par. 6.10) is whether the intention to preserve heritage items could "result in a present obligation such that an entity has little or no realistic alternative to avoid an outflow of resources". This issue reflects Mautz's (1988) famous provocation that heritage items should count as liabilities rather than assets. However, it seems to be still perceived as relevant only in the academic realm, while raising very little concern among practitioners. 
Among the national standard setters, in particular, only the UK and Ireland have shown some interest, in that they mandate a disclosure of the entity's policy for the acquisition, preservation, management and disposal of heritage assets, either in the Notes or in a document that is crossreferenced from the financial statements. In Lithuania, plans exist to amend national standards in the future to consider this aspect. All other countries have so far kept silent.

Similarly, the IPSASB's position, which was supported by the large majority of respondents $(77 \%)$, is that:

The entity should not $[\ldots]$ recognize a liability $(P V-$ Chapter 6$)$.

More specifically, the Consultation Paper does recognize that "entities holding heritage items [...] have a moral duty to expend resources to preserve those items" (par. 6.10). However, it argues that "a moral duty does not give rise to a present obligation and therefore a liability" (par. 6.4).

Moreover, it does relay the position whereby "a liability should be recognized to reflect [the resource outflows involved in holding heritage items], including deferred outflows, where deferral could be by comparison to an agreed cycle of maintenance or with respect to some other criteria". At the same time, however, it claims that the very "ability to defer these outflows suggests that an entity does not have a present obligation for the outflow of resources" (par. 6.6).

\subsection{Presentation of information about heritage}

The final chapter of the Consultation Paper discusses whether the special characteristics of heritage items have implications for the presentation of information in general purpose financial reports. Once again, the IPSASB's position is that they do not, so that:

\section{Information about heritage should be presented in line with existing IPSASB pronouncements ( $P V-$ Chapter 7$)$.}

This position was not motivated on specific grounds. Rather, it was presented as the logical consequence of the previous proposals. Once again, the majority of respondents (57\%) agreed, but somehow qualified their agreement. In particular, two-thirds of the "agree" respondents identified additional presentation requirements, also because they were unsure about what the reference to "existing IPSASB pronouncements" would imply. These suggested presentation requirements can be broadly classified into six groups: (i) dedicated financial statement line items; (ii) rationale for inclusion in (or exclusion from) the balance sheet; (iii) methodology used to value the assets, if included in the balance sheet; (iv) information on items excluded from the balance sheet, or included at a symbolic value; (v) specific qualitative information, including a description of the entity's stewardship responsibilities and related policies; and (vi) heritage-specific reports. The Appendix (Table E) provides a more complete summary of such suggestions, relates them to the disclosures currently required by national standards, and adds a few further items drawn from those same national standards. 


\section{CONCLUSIONS}

This paper sought to better understand the convergence of private and public sector accounting standards by looking at the conceptual and practical issues relating to heritage - a topic that is particularly relevant for the public sector context. This was done through a qualitative documentary analysis based on the IPSASB's Consultation Paper on heritage, the responses to the consultation, and the standards currently adopted by 15 European jurisdictions, reflecting a variety of country sizes and administrative traditions.

As made evident by the literature review, the definition, recognition, and measurement of heritage under accrual accounting have been the subject of practical and scholarly attention, as well as of a heated debate, for a few decades. In spite of this, the matter appears to be far from settled. National standards, the standard proposed internationally, and the reactions of respondents to the latter, all show that the magnitude and nature of the divergences of views, proposals, experiences on how heritage should be recognized and reported remain important and perhaps unlikely to find a convincing solution. Interestingly, this appears to reflect the variety of stakeholders and related interests which surrounds public sector accounting and reporting issues.

The Consultation Paper is influenced by a desired convergence between IPSASs and their private sector counterparts (IAS/IFRS). It seemingly suggests, therefore, that heritage can be described, measured, and reported using conceptual lenses which, though with adaptations, find their roots in private sector accounting. These lenses, however, tend to downplay the specificities of heritage items and their differences from private sector assets. To support its arguments, the IPSASB proposes various forms of hybridization, including extensions of generally accepted definitions which, however, may become complex to apply in practice or negatively affect disclosure. More generally, it largely overlooks the existing conceptual and practical complications, as highlighted in the literature, emerging in the variety of approaches adopted by national jurisdictions, and raised by stakeholders in their responses. The end result is a system of definitions and principles for recognition and measurement which reflect an inappropriate view of heritage.

Indeed, the responses submitted to the IPSASB may at first appear supportive of the proposals, but actually cast serious doubts as to their soundness and applicability. The IPSASB's definition and elaborations are criticised as being vague and incomplete. The responses express uncertainties about the interpretation of terms like control, economic benefits and service potential, and about the elusiveness of a reliable measurement - issues that are crucial when following the IPSASB's line of reasoning. In short, the responses suggest that the special characteristics of heritage assets require ad hoc technical solutions and cannot simply be waved aside through a general reference to regular assets. 
However, such solutions are not readily available, as witnessed by the national experiences. The diversity of approaches adopted by the countries under analysis is testimony to the impossibility of actually defining, measuring, and recognizing heritage as assets in an uncontroversial, unanimous and practically feasible way. They also reveal a variety of local underlying situations and sensitivities that may be difficult to reconcile at a global level.

Finally, as highlighted by some respondents, it is worth noticing that the IPSASB's principlesbased approach, based on a definition of assets primarily designed for the private sector, may still lead to the exclusion of the majority of heritage items, as they do not fulfil the criteria for recognition. This would have major consequences on the quality of the information provided by governmental financial reports, in terms of completeness, verifiability, and comparability.

In the light of calls for increased measurement and reporting of public sector "assets", and specifically for the definition of standards to recognize heritage, the present analysis suggests the need to strongly reconsider whether the convergence between public and private sector standards is desirable, feasible, and effective. Unfortunately, it appears that there may not be shortcuts to ensure transparency on heritage and to properly define, recognize, and measure them. An excessive reliance on a private-sector model may produce an "illusion of convergence" because the mere adoption or interpretation of private sector (for-profit) accounting standards would not focus on the uniqueness of government accounting. As such, the risks of embracing simplified or hybrid forms of accounting and reporting for heritage should be more seriously considered. While reporting on heritage is important, it is fundamental to ensure that it is kept distinct from reporting on government's regular operations, in order to appreciate its specific value, nature, and features. As a final note, if due consideration was given to the governmental context, then heritage items would not be called "assets" in the first place, let alone proposing to account for them in a similar way. Reference to "heritage assets" is a demonstration of attempted "hi-jacking" of a priceless hostage by private sector accrual accounting practices.

All in all, this paper provides a "pluralistic" view of the current state of the art in the supposed "convergence" between public and private sector accounting standards, with attention to one of the most debated matters, i.e., heritage. In doing so, it provides further evidence that convergence is far from being reached, nor is it conceptually appropriate and practically feasible, with a number of critical issues still remaining unresolved.

As any piece of research, this paper has limitations, which also suggest possible future research avenues. Two main limitations stand out.

A first limitation stems from the specific method used to collect data, i.e. documentary analysis (Bowen 2009). While documentary analysis has several advantages, it is not particularly suitable to grasp the different views of relevant stakeholders on a given issue. Future research may attempt to triangulate the results of this study on the basis of interviews with relevant actors in the different countries. Moreover, documentary analysis is also constrained by the availability of documentation. As such, our study includes only the 
countries for which documents were accessible. Further studies, relying on a combination of data collections tools, may expand the analysis to other countries to provide a more comprehensive picture. Finally, specifically for our study, the analysis of the documents had often to be intermediated by fellow academics in order to overcome language barriers, with the potential loss or distortion of information.

Secondly, in terms of purposes, the study contributes to a better understanding of the state of the art in national and international accounting standards on heritage assets. To do so, while it highlights the different approaches emerging across countries, it cannot provide a detailed description of individual country experiences, let alone identify the underlying explanatory factors and their consequences ${ }^{6}$. Future research should thus compare and contrast in more depth the different national approaches, experiences, motivations as well as their consequent results.

\footnotetext{
${ }^{6} \mathrm{We}$ are indebted to one of the reviewers for this useful suggestion.
} 


\section{REFERENCES}

Adam, B., Mussari, R. and Jones, R. (2011), "The Diversity of Accrual Policies in Local Government Financial Reporting: An Examination of Infrastructure, Art and Heritage Assets in Germany, Italy and the UK", Financial Accountability \& Management, Vol.27 No.2, pp.107-133.

Aversano, N. and Christiaens, J. (2014), "Governmental Financial Reporting of Heritage Assets from a User Needs Perspective", Financial Accountability \& Management, Vol.30 No.2, pp.150-174.

Barton, A. (2000), "Accounting for public heritage facilities - assets or liabilities of the government?", Accounting, Auditing \& Accountability Journal, Vol.13 No.2, pp.219236.

Barton, A. (2005), "The conceptual arguments concerning accounting for public heritage assets: a note", Accounting, Auditing \& Accountability Journal, Vol.18 No 3, pp.434440.

Biondi, L. and Lapsley, I. (2014), "Accounting, transparency and governance: the heritage assets problem", Qualitative Research in Accounting \& Management, Vol.11 No.2, pp.146-164.

Bowen, G. A. (2009) "Document analysis as a qualitative research method." Qualitative Research Journal, Vol. 9 No. 2, pp. 27-40.

Boyne, G. A. (2002), "Public and Private Management: What's the Difference?", Journal of Management Studies, Vol.39 No.1, pp.97-122.

Boyne, G., Poole, M., and Jenkins, G. (1999), "Human Resource Management in the Public and Private Sectors: An Empirical Comparison", Public Administration, Vol.77 No.2, pp.407-420.

Carnegie, G. D. and Wolnizer, P. W. (1995), "The Financial Value of Cultural, Heritage And Scientific Collections: An Accounting Fiction", Australian Accounting Review, Vol.5 No.9, pp.31-47.

Carnegie, G. D. and Wolnizer, P. W. (1996), "Enabling accountability in museums", Accounting, Auditing \& Accountability Journal, Vol.9 No.5, pp.84-99.

Carnegie, G. and Wolnizer, P. (1999), "Unravelling the Rhetoric About the Financial Reporting of Public Collections as Assets", Australian Accounting Review, Vol.9 No.17, pp.16-21. 
Christiaens, J. (2004), "Capital assets in governmental accounting reforms: comparing Flemish technical issues with international standards", European Accounting Review, Vol.13 No.4, pp.743-770.

Christiaens, J., Rommel, J., Barton, A. and Everaert, P. (2012), "Should all capital goods of governments be recognised as assets in financial accounting?", Baltic Journal of Management, Vol.7 No 4, pp.429-443.

Ellwood, S. and Greenwood, M. (2016), "Accounting for heritage assets: Does measuring economic value 'kill the cat'?", Critical Perspectives on Accounting, Vol.38, pp.1-13.

Ellwood, S. and Newbury, S. (2006), "A bridge too far: a common conceptual framework for commercial and public benefit entities". Accounting and Business Research, Vol.36 No.1, pp.19-32.

EY (2017), Accounting treatment of heritage assets with a view to financial reporting requirements under the future European Public Sector Accounting Standards (EPSAS), Paper dated 10 March 2017, presented to EPSAS Working Group of the European Commission in Luxembourg.

Glazer, A.S. and Jaenicke, H.R. (1991), "The Conceptual Framework, Museum Collections, and User-Oriented Financial Statements", Accounting Horizons, Vol.5 No.4, pp.2843.

Grossi, G. and Steccolini I. (2015), "Pursuing private or public accountability in the public sector? Applying IPSASs to define the reporting entity in municipal consolidation", International Journal of Public Administration, Vol.38 No.4, pp.325-334.

Harris, J.E. and Murti, V.N. (1998), "Response to Fixed Assets Reporting: A Research Note", Public Budgeting \& Finance, Vol.18, pp.119-123.

Hone, P. (1997), "The Financial Value of Cultural, Heritage and Scientific Collections: A Public Management Necessity", Australian Accounting Review, Vol.7 No.13, pp.3843.

IMF (2018), Fiscal Monitor, 2018, Managing Public Wealth, October 2018.

IPSASB (2017a), "Financial Reporting for Heritage in the Public Sector, Consultation Paper issued in April 2017”, available at: http//www.ifac.org (accessed 31 August 2017)

IPSASB (2017b), "Heritage, Agenda Item 7 on IPSASB agenda for meeting held 5-8 December 2017, in Toronto, Canada", available at: http//www.ifac.org (accessed 31 January 2018) 
Lapsley, I. (1988),"Research in Public Sector Accounting: An Appraisal", Accounting, Auditing \& Accountability Journal, Vol.1 No.1, pp.21-33.

Mautz, R.K. (1988), "Editorial: monuments, mistakes and opportunities", Accounting Horizons, Vol.2 No.2, pp.123-8.

Meyer, R.E. and G. Hammerschmid. (2010), "The Degree of Decentralization and Individual Decision Making in Central Government Human Resource Management: A European Comparative Perspective", Public Administration, Vol.88 No.2, pp.455-78.

Micallef, F. and Peirson, G. (1997), "Financial Reporting of Cultural, Heritage, Scientific and Community Collections", Australian Accounting Review, Vol.7 No.13, pp.31-37.

Nutt, P., and Backoff, R. (1993), "Organizational publicness and its implications for strategic management", Journal of Public Administration Research and Theory, Vol.3 No.2, pp.209-231.

Pallot, J. (1992), "Elements of a Theoretical Framework for Public Sector Accounting", Accounting, Auditing \& Accountability Journal, Vol.5 No.1, pp. null.

Pollitt, C. and G. Bouckaert. 2011. 'Public Management Reform: A Comparative Analysis New Public Management, Governance, and the Neo-Weberian State', International Review of Administrative Sciences, Vol.78 No.1, pp.180-82.

Rayney, H., Backoff, R. and Levine, C. (1976), "Comparing public and private organizations", Public Administration Review, Vol.36, pp.233-244.

Stanton, P. J. and Stanton, P. A. (1997), "Governmental accounting for heritage assets: economic, social implications", International Journal of Social Economics, Vol.24 No.7/8/9, pp.988-1006.

Steccolini, I., (2019) "Accounting and the post-new public management: Re-considering publicness in accounting research", Accounting, Auditing \& Accountability Journal, Vol. 32, No 1, pp.255-279.

Ström, S. (1997), "Accounting for Assets in the Public Sector-Ifs and Hows", European Accounting Association Congress, April 1997. 